\title{
DIFERENCIAÇÃO CATIÔNICA DE BENTONITAS POR INFRAVERMELHO: UM ESTUDO DOS EFEITOS DA HIDRATAÇÃO DOS CÁTIONS TROCÁVEIS
}

\author{
Andréia O. Rodrigues ${ }^{\mathrm{a}}$, Rômulo S. Angélica ${ }^{\mathrm{a},(0)}$ e Simone P.A. Paz ${ }^{\mathrm{a}, \mathrm{b}, *,(1)}$ \\ anstituto de Geociências, Universidade Federal do Pará, 66075-110 Belém - PA, Brasil \\ ${ }^{\text {b} F a c u l d a d e ~ d e ~ E n g e n h a r i a ~ Q u i ́ m i c a, ~ I n s t i t u t o ~ d e ~ T e c n o l o g i a, ~ U n i v e r s i d a d e ~ F e d e r a l ~ d o ~ P a r a ́, ~ 66075-110 ~ B e l e ́ m ~-~ P A, ~ B r a s i l ~}$
}

Recebido em 27/05/2020; aceito em 09/11/2020; publicado na web em 20/01/2021

\begin{abstract}
CATIONIC DIFFERENTIATION OF BENTONITES BY INFRARED: A STUDY OF THE HYDRATION EFFECTS OF EXCHANGEABLE CATIONS. In the bentonite industry, the most common procedure for quality control of the ore and the sodium activation process is the swelling method. However, this tool is restricted only to the differentiation of the sodium and non-sodium types, not considering the other cationic varieties. The objective of this study was to establish parameters for cationic differentiation of bentonites based on Near Infrared (NIR) and Medium (MIR) spectroscopy, which proved to be an effective technique in the cationic differentiation of bentonites using the characteristic bands " $7072 \mathrm{~cm}^{-1}$ " and " 3620 and $3430 \mathrm{~cm}^{-1}$ " under the condition of the dry-hydrated sample and not under the anhydrous condition. NIRS can be considered a measure of great scientific and technological contribution, as it allows the cationic differentiation of bentonites in a practical way and with low analytical cost.
\end{abstract}

Keywords: bentonite; infrared; cationic type; hydration.

\section{INTRODUÇÃO}

Bentonita é uma argila industrial composta, predominantemente, pelo argilomineral montmorillonita - subespécie mais abundante do grupo esmectita. Este argilomineral é um filossilicato 2:1, com camadas constituídas por duas folhas tetraédricas e uma octaédrica e o seu empilhamento dá origem aos tactóides. O espaço intercamada é ocupado por cátions trocáveis hidratados, tais como: $\mathrm{Na}^{+}, \mathrm{K}^{+}$, $\mathrm{Mg}^{2+}$ e $\mathrm{Ca}^{2+}$, os quais são compensadores de carga. Dependendo dos tipos e quantidades dos cátions, a montmorillonita pode apresentar propriedades adequadas ou não a certa aplicação. ${ }^{1-4}$ Tecnologicamente, a bentonita é classificada apenas como sódica natural, sódica ativada e cálcica, embora exista e seja muito comum outras variedades catiônicas, tais como: magnesiana, potássica e mista (no Brasil também chamada policatiônica). ${ }^{5}$

O tipo sódica é caracterizada por sua elevada capacidade de inchamento e boas propriedades tixotrópicas (tixotropia é uma propriedade de afinamento de um fluido por cisalhamento, o qual dependente do tempo. Certos géis ou fluidos viscosos sob condições estáticas, tornam-se mais finos e menos viscosos quando agitados, e fluirão ao longo do tempo que permanecer sob agitação, tensão de cisalhamento ou tensão de outro modo), ${ }^{6}$ o que a destina para diversas aplicações industriais, tais como: fluido de perfuração de poços de petróleo, pelotização de minério de ferro, molde de fundição, entre muitas outras aplicações. As demais variedades não apresentam as mesmas características, o que limita sua aplicabilidade, obstáculo muitas vezes resolvido por meio do tratamento químico conhecido como ativação sódica - processo de troca catiônica usando $\mathrm{Na}_{2} \mathrm{CO}_{3}{ }^{1,6,7}$ Este procedimento é bastante comum no Brasil, pois seus depósitos são predominantemente policatiônicos.

As principais minas do Brasil encontram-se no estado da Paraíba. De acordo com o Departamento Nacional de Produção Mineral, ${ }^{8}$ o estado da Paraíba é responsável por $60,1 \%$ da produção de bentonita bruta e $54,7 \%$ da beneficiada (ativada + moída); sendo o principal uso da bentonita ativada, a pelotização de minério de ferro.

Um problema recorrente na indústria de bentonita ativada

\footnotetext{
*e-mail: paz@ufpa.br
}

sodicamente é aquele que vem sendo chamado de desativação sódica, perda das propriedades $\sim 60$ dias. Esse problema tem sido associado a ampla variabilidade química das bentonitas de origem, principalmente, com relação à composição dos cátions trocáveis, informação ausente, quando se tem como principal método de classificação o inchamento. Essa ferramenta restringe-se apenas à diferenciação do tipo sódico e não-sódico, não contemplando as demais variedades catiônicas.

O conhecimento mais preciso do tipo catiônico ajudaria na implementação de ajustes físico-químicos, tais como: dosagem de $\mathrm{Na}_{2} \mathrm{CO}_{3}$, tempo de residência e manutenção controlada de umidade no volume de controle; consequentemente, ajudaria nas propriedades reológicas e nas propriedades relacionadas a água (umidade e hidratação). A qualidade do produto de acordo com suas propriedades é crucial para aplicações tecnológicas, principalmente, fluidos de perfuração e moldes de fundição. Para isso, os fatores mencionados anteriormente, devem ser controlados de perto, pois afetam as especificações finais da bentonita ativada. ${ }^{9,10}$ Contudo, a determinação do tipo catiônico requer procedimentos laboriosos, com trocas catiônicas diárias (entre 3 a 6 dias) e análises químicas via úmida e/ou instrumental, o que para a pesquisa é praticável, mas para uma indústria de beneficiamento primário passa a ser pouco provável.

A espectroscopia de Infravermelho é uma técnica analítica instrumental importante na investigação das características químicas dos argilominerais, principalmente para o estudo da hidratação de esmectitas. A região do espectro eletromagnético usada, normalmente, para investigar a interação esmectita- $\mathrm{H}_{2} \mathrm{O}$ é o médio (MIR); todavia, a espectroscopia na região próximo (NIR) também oferece essa possibilidade. O método por reflectância difusa é especialmente apropriado na região NIR, onde, ao contrário da região MIR, não é necessária diluição da amostra e, portanto, a análise de IV pode ser muito rápida e não destrutiva. ${ }^{11-14}$

Sobre usos do espectro no infravermelho na investigação química e cristaloquímica dos materiais, vale citar, na íntegra, o "olhar" interpretativo descrito por Pavia et al. (2009): "Como cada tipo de ligação tem sua própria frequência natural de vibração, $e$ como dois tipos idênticos de ligações em dois diferentes compostos estão em dois ambientes levemente diferentes, os padrões de 
absorção no infravermelho, ou espectro de infravermelho, em duas moléculas de estruturas diferentes nunca são exatamente idênticos. Apesar de as frequências absorvidas nos dois casos poderem ser iguais, jamais os espectros infravermelhos (os padrões de absorção) de duas moléculas diferentes serão idênticos. Assim,o espectro infravermelho pode servir para moléculas da mesma forma que impressões digitais servem para seres humanos. Quando se compararam os espectros infravermelhos de duas substâncias que se acredita serem idênticas, pode-se descobrir se elas são, de fato, idênticas. Se os espectros infravermelho coincidirem pico a pico (absorção a absorção), na maioria das vezes as duas substâncias serão idênticas." ${ }^{15}$

Nesse contexto, buscou-se nesse trabalho estabelecer parâmetros de classificação catiônica de bentonitas via uma técnica instrumental considerada de fácil aquisição monetária e também de fácil operação, por meio de uma investigação de diferenciação química via infravermelho usando sete bentonitas já bem caracterizadas e conhecidas quanto ao tipo catiônico.

\section{PARTE EXPERIMENTAL}

\section{Bentonitas}

As sete bentonitas utilizadas nesse trabalho estão identificadas na Tabela 1, classificadas de acordo com seu local de origem, cor e tipo de cátion. Dessas, quatro são provenientes de minas do estado da Paraíba: Mina Bravo, no município de Boa Vista e Mina Campos Novos, em Cubati; a bentonita Formosa é proveniente de uma ocorrência, no município de Formosa da Serra Negra, estado do Maranhão; e dois materiais de referência, obtidos do banco de padrões da Clay Minerals Society (CMS): a bentonita sódica de Wyoming (SWy-2) e a bentonita cálcica do Arizona (SAz-1).

\section{PREPARAÇÃO DE AMOSTRAS}

\section{Separação da fração argila}

As amostras foram preparadas segundo o procedimento padrão de concentração-separação da fração argila. O material foi desagregado e disperso em água deionizada, em banho de ultrassom por $30 \mathrm{~min}$. A suspensão foi classificada em peneira de 250 malhas ABNT $(0,063$ $\mathrm{mm}$ ). A suspensão passante foi centrifugada a $1400 \mathrm{rpm}$ por $4 \mathrm{~min}$ (centrífuga NovaTécnica NT820) e classificada em: fração silte (sedimentada, $62 \mu \mathrm{m}>$ tamanho de partícula $>2 \mu \mathrm{m}$ ) e fração argila (sobrenadante, tamanho de partícula $<2 \mu \mathrm{m}$ ). Para desaguamento da fração argila, a suspensão sobrenadante foi centrifugada a $2800 \mathrm{rpm}$ por $10 \mathrm{~min}$, finalizando com $1^{\mathrm{a}}$ secagem a $60^{\circ} \mathrm{C}$, em estufa.

\section{$2^{a}$ Secagem e desidratação}

Duas condições de pré-tratamento térmico foram avaliadas: (a) $2^{\text {a }}$ secagem a $105^{\circ} \mathrm{C}$ por $24 \mathrm{~h}$ e (b) desidratação a $400{ }^{\circ} \mathrm{C}$ por $2 \mathrm{~h}$.

\section{Análises}

Difratometria de raios $X(D R X)$ : foi realizada em um difratômetro modelo EMPYREAN (PANalytical), equipado com um goniômetro $\theta-\theta$, tubo de raios $X$ cerâmico com ânodo de cobalto $\left(\mathrm{K} \alpha 1=1,789010 \AA\right.$ ) , filtro $\mathrm{K} \beta$ de Fe e detector PIXCEL ${ }^{3 \mathrm{D}}$-Medpix ${ }^{3}$ $1 \times 1$. As condições de análise foram: varredura de 4 a $43^{\circ} 2 \theta, 40 \mathrm{kV}$, $35 \mathrm{~mA}$; tamanho do passo de $0,02^{\circ} 2 \theta$; tempo por passo de $30 \mathrm{~s}$; fenda divergente de $1 / 4^{\circ}$ e antiespalhamento de $1 / 2^{\circ}$; máscara de $10 \mathrm{~mm} \mathrm{e}$ movimentação circular da amostra com frequência de 1 rotação $\mathrm{s}^{-1}$.

Espectrometria de fluorescência de raios $X(F R X)$ : foi realizada em um espectrômetro WDS-sequencial, modelo Axios-Minerals (PANalytical), tubo de raios X cerâmico com ânodo de ródio e nível de potência máxima de $2,4 \mathrm{~kW}$. As amostras foram preparadas no modo de disco fundido ( $1 \mathrm{~g}$ de amostra $+6 \mathrm{~g}$ de tetraborato de lítio). A análise foi realizada por meio do software SuperQ Manager da PANalytical, aplicação quantitativa Standardless-Omnian. A medida de perda ao fogo (P.F.) foi realizada por queima a $1000^{\circ} \mathrm{C}$ por $1 \mathrm{~h}$, em forno mufla.

Cátions trocáveis e capacidade de troca catiônica (CTC): o método utilizado foi aquele para averiguação de fertilidade de solo. ${ }^{21}$ Os cátions $\mathrm{Na}^{+}$e $\mathrm{K}^{+}$foram extraídos com solução de Mehlich $(\mathrm{HCl}$ $0,05 \mathrm{~mol} \mathrm{~L}^{-1}+\mathrm{H}_{2} \mathrm{SO}_{4} 0,0125 \mathrm{~mol} \mathrm{~L}^{-1}$ ) na relação argila/extrato de 1:10 e medidos por um fotômetro de chama (modelo BFC 150, Benfer). Os cátions $\mathrm{Mg}^{2+}$ e $\mathrm{Ca}^{2+}$ foram extraídos com solução $\mathrm{KCl} 1 \mathrm{~mol} \mathrm{~L}^{-1} \mathrm{e}$ medidos somados $\left(\mathrm{Mg}^{2+}+\mathrm{Ca}^{2+}\right)$ por titulação complexométrica com sal dissódico de EDTA $0,0125 \mathrm{~mol} \mathrm{~L}^{-1}$, usando negro de eriocromo $\mathrm{T}$ como indicador. Para determinar somente o $\mathrm{Ca}^{2+}$, realizou-se a titulação complexométrica com EDTA, usando o ácido calconcarbonico como indicador. Calculou-se o teor de $\mathrm{Mg}^{2+}$ pela diferença.

Espectroscopia de Infravermelho (IV): foi realizada em um espectrofotômetro da marca Thermo Scientific, modelo Nicolet iS50 FT-IR. Para as medidas na região NIR foi utilizado um divisor de feixe (beam splitter) de $\mathrm{CaF}_{2}$ e detector de $\mathrm{PbSe}$; para a região MIR foi usado beam splitter de $\mathrm{KBr}$ e detector de KBr DTGS. Para cada amostra, foram registrados 100 scans com resolução de $8 \mathrm{~cm}^{-1}$ nas regiões espectrais $4.000-400 \mathrm{~cm}^{-1}$ (MIR) e $11.000-4.000 \mathrm{~cm}^{-1}$ (NIR). Na região do NIR, todas as medidas foram realizadas usando reflectância difusa (DRIFT), modo de preenchimento randômico e sem adição de $\mathrm{KBr}$, enquanto na região MIR, todas as medidas foram por transmitância no modo de pastilha prensada ( $1 \mathrm{mg}$ de amostra para $150 \mathrm{mg}$ de $\mathrm{KBr}$ ).

\section{RESULTADOS E DISCUSSÃO}

\section{Composição química e mineralógica}

Os difratogramas de raios X são apresentados na Figura 1. Em todas as amostras predomina a presença de esmectita do tipo

Tabela 1. Identificação das bentonitas

\begin{tabular}{|c|c|c|c|}
\hline Bentonitas & Origem & Cor & Tipo de cátions trocáveis \\
\hline Bofe & Boa Vista - PB - BR & bege & policatiônica ${ }^{16,17,18}$ \\
\hline Verde & & verde & \\
\hline Verde claro & & verde mais claro & \\
\hline Verde escuro & Cubati - PB - BR & verde mais escuro & policatiônica $^{18}$ \\
\hline Formosa & Formosa da Serra Negra - MA - BR & marrom avermelhado & magnesiana $^{19,20}$ \\
\hline SWy-2 & Wyoming - EUA & branco acinzentado & sódica $^{19,20}$ \\
\hline SAz-1 & Arizona - EUA & branco & cálcica $^{19,20}$ \\
\hline
\end{tabular}


montmorillonita, com a reflexão principal " $d_{001}$ " entre 1,2-1,55 nm. As outras importantes reflexões na caracterização de esmectitas são: " $d_{100}$ " $\sim 0,446 \mathrm{~nm}$ e " $d_{060}$ " 0,149 nm, esta última diz-se impressão digital de esmectitas dioctaédricas. ${ }^{20,22,23}$

Na Figura 1a, observa-se que a Formosa e SAz-1 apresentam " $d_{001}$ " 1,5 nm, valor típico de montmorillonitas com cátions trocáveis do tipo $\mathrm{Ca}^{2+}, \mathrm{Mg}^{2+}$ ou policátions, tal como as montmorillonitas policatiônicas apresentadas na Figura 1b; enquanto, a SWy-2 apresenta " $d_{001}$ " 1,2 nm, valor típico de montmorillonita com cátions trocáveis do tipo $\mathrm{Na}^{+}$(Figura 1a). ${ }^{24,25}$ Além do argilomineral montmorillonita, foi detectado ainda traços de caulinita $(0,718$ e $0,256 \mathrm{~nm})$, cristobalita $(0,413 \mathrm{~nm})$, quartzo $(0,334 \mathrm{~nm})$ e anatásio $(0,352 \mathrm{~nm})$, nas amostras da Figura $1 \mathrm{~b}$.

A composição química está apresentada na Tabela 2. Nota-se que os teores de $\mathrm{SiO}_{2}$ e $\mathrm{Al}_{2} \mathrm{O}_{3}$ são predominantes em todas as amostras. Os altos teores de $\mathrm{Fe}_{2} \mathrm{O}_{3}$ são típicos de bentonitas brasileiras. Notase que as bentonitas brasileiras apresentam menores teores de $\mathrm{CaO}$, quando comparadas as americanas SAz-1 e SWy-2, sendo SWy-2 a que apresenta o maior teor de $\mathrm{Na}_{2} \mathrm{O}$, entre todas. Os teores de $\mathrm{MgO}$ são, inconfundivelmente, altos em todas as amostras, reforçando a presença marcante do cátion divalente $\mathrm{Mg}^{2+}$ nos sítios octaédricos, o que caracteriza a espécie montmorillonita no grupo esmectita. Finalmente, ressalta-se que o tipo catiônico não pode ser determinado a partir da composição química total, é necessário que se analise os cátions trocáveis, tal como vide a seguir.

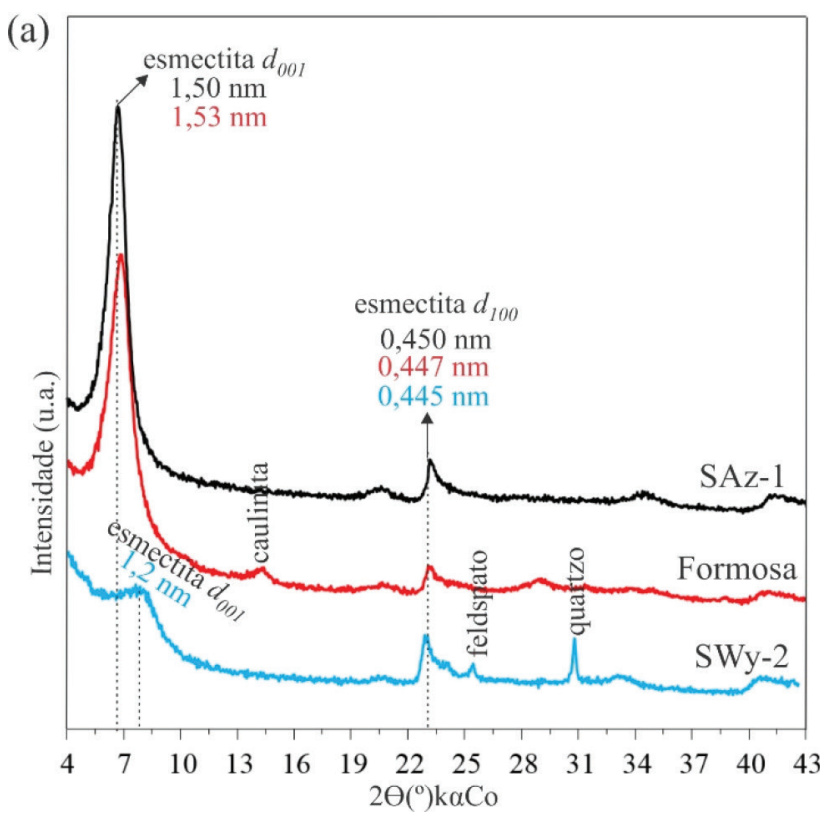

\section{Cátions trocáveis e capacidade de troca catiônica}

De acordo com os teores de cátions trocáveis (Tabela 3), as bentonitas são classificadas como:

(a) "Homocatiônicas": SWy-2 (sódica), Formosa (magnesiana) e SAz-1 (cálcica);

(b) Policatiônicas: Bofe, Verde, Verde escuro e Verde claro.

A CTC de um argilomineral é a quantidade de cátions que este pode adsorver e trocar, uma característica química que exerce total influência sobre as reações topoquímicas nas esmectitas (reações topoquímicas são aquelas que ocorrem apenas em regiões específicas de um sistema). ${ }^{22}$ A CTC de uma esmectita é resultante do desequilíbrio das cargas elétricas na estrutura cristalina devido às substituições isomórficas nos sítios tetraédricos e octaédricos, às ligações químicas quebradas nas arestas dos cristalitos ou tactóides e à interação dos cátions $\mathrm{H}_{3} \mathrm{O}^{+}$com as cargas nestas ligações quebradas. Tal desequilíbrio gera cargas negativas e para neutralizá-las existem cátions trocáveis, que estão fixos eletrostaticamente ao longo das faces e nas intercamadas..$^{22,23,26,27} \mathrm{O}$ poder de troca de um cátion será maior, quanto maior for a sua valência e menor a sua hidratação. Entre cátions de mesma valência, a seletividade aumenta com o raio iônico, em função do decréscimo do grau de hidratação, pois quanto maior for o volume do íon, mais fraco será seu campo elétrico na solução e, conseqüentemente, menor o grau de hidratação. No caso de

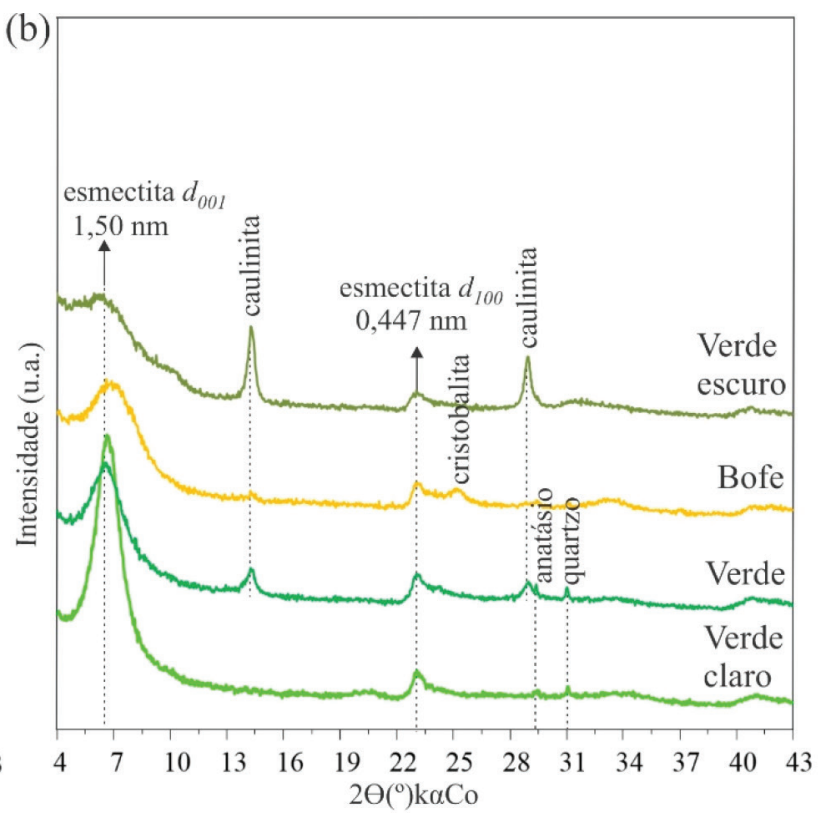

Figura 1. DRX da fração argila: (a) Formosa, SAz-1 e SWy-2 e (b) Bofe, Verde, Verde escuro e Verde claro

Tabela 2. Composição química das bentonitas

\begin{tabular}{|c|c|c|c|c|c|c|c|c|c|c|}
\hline \multirow{2}{*}{ Bentonita } & \multicolumn{10}{|c|}{ Constituinte ( $\%$ massa) } \\
\hline & $\mathrm{SiO}_{2}$ & $\mathrm{Al}_{2} \mathrm{O}_{3}$ & $\mathrm{Fe}_{2} \mathrm{O}_{3}$ & $\mathrm{MgO}$ & $\mathrm{CaO}$ & $\mathrm{K}_{2} \mathrm{O}$ & $\mathrm{Na}_{2} \mathrm{O}$ & $\mathrm{TiO}_{2}$ & $\mathrm{P}_{2} \mathrm{O}_{5}$ & P.F. \\
\hline Formosa & 51,6 & 21,6 & 8,5 & 3,9 & 0,29 & 0,90 & - & 0,47 & - & 12,7 \\
\hline SWy-2 & 63,7 & 18,8 & 3,7 & 2,2 & 1,47 & 0,64 & 1,98 & 0,13 & $<0,1$ & 7,2 \\
\hline SAz-1 & 60,8 & 17,2 & 1,4 & 5,9 & 2,9 & 0,16 & - & 0,19 & $<0,1$ & 11,3 \\
\hline Bofe & 63,6 & 14,7 & 6,2 & 1,9 & 0,43 & 0,23 & 0,28 & 0,74 & $<0,1$ & 11,8 \\
\hline Verde & 54,1 & 21,6 & 8,1 & 2,2 & 0,37 & 1,64 & 0,71 & 1,57 & - & 9,8 \\
\hline Verde claro & 55,3 & 19,2 & 8,2 & 3,8 & 0,86 & 0,78 & 0,42 & 0,99 & - & 10,4 \\
\hline Verde escuro & 50,3 & 19,8 & 10,5 & 2,8 & 0,27 & 1,58 & 0,34 & 0,69 & $<0,1$ & 13,6 \\
\hline
\end{tabular}

P.F.: Perda ao fogo determinada com a queima a $1000^{\circ} \mathrm{C}$ por $1 \mathrm{~h}$; - : abaixo do limite de detecção. 
cátions monovalentes, a seletividade segue a seguinte seqüência: $\mathrm{K}^{+}$ $>\mathrm{Na}^{+}>$. Para cátions bivalentes a seqüência é: $\mathrm{Ca}^{2+}>\mathrm{Mg}^{2+} \cdot{ }^{25}$ Dessa maneira, os valores de CTC para as bentonitas "homocatiônicas" seguem a seletividade descrita anteriormente: $\mathrm{SAz}-1$ (cálcica) > Formosa (magnesiana) $>$ SWy-2 (sódica). Já os valores de CTC para as bentonitas policatiônicas, estes se apresentam variável em função de uma distribuição menos desigual entre os teores de cátions trocáveis.

Tabela 3. Cátions trocáveis e CTC das bentonitas

\begin{tabular}{lccccc}
\hline \multirow{2}{*}{ Bentonita } & \multicolumn{3}{c}{$\mathrm{cmol}_{\mathrm{c}} / \mathrm{dm}^{3}$ de $\operatorname{argila~seca}$} & \multirow{2}{*}{$*$ *TC } \\
\cline { 2 - 5 } & $\mathrm{Ca}^{2+}$ & $\mathrm{Mg}^{2+}$ & $\mathrm{K}^{+}$ & $\mathrm{Na}^{+}$ & \\
\hline SWy-2 & 12,70 & 10,20 & 0,85 & 6,84 & 30,59 \\
Formosa & 7,70 & 43,80 & 0,23 & 0,34 & 52,07 \\
SAz-1 & 47,50 & 8,30 & 0,29 & 0,50 & 56,59 \\
Bofe & 8,60 & 21,40 & 0,19 & 5,20 & 35,38 \\
Verde & 12,50 & 35,50 & 0,53 & 6,19 & 54,72 \\
Verde claro & 20,00 & 48,00 & 0,42 & 4,06 & 72,5 \\
Verde escuro & 9,60 & 25,20 & 0,74 & 4,33 & 39,87 \\
\hline
\end{tabular}

$* \mathrm{CTC}=\mathrm{Ca}^{2+}+\mathrm{Mg}^{2+}+\mathrm{K}^{+}+\mathrm{Na}^{+}$

\section{Diferenciação catiônica por Infravermelho}

As duas bandas de absorção IV-MIR - características da informação "cátions trocáveis + água de hidratação" na intercamada da montmorillonita - obtidas para SWy-2 (sódica), Formosa (magnesiana) e SAz-1 (cálcica) são exibidas na Figura 2. As complexas bandas " 3620 e $3430 \mathrm{~cm}^{-1}$ " são atribuídas ao alongamento da ligação $\mathrm{O}-\mathrm{H}$ de grupos hidroxila estruturais e ao alongamento da ligação O-H das moléculas de água, que estão na intercamada solvatando os cátions trocáveis. A banda em frequência mais alta no par se deve à vibração assimétrica, enquanto a banda em frequência mais baixa resulta da vibração simétrica. Os alongamentos- $\mathrm{OH}$ de grupos hidroxila estruturais, pertencentes ao framework da montmorillonita anidra, são os responsáveis pela impressão digital do argilomineral 2:1 montmorillonita, uma vez que, as duas bandas IV-MIR "3620 e $3430 \mathrm{~cm}^{-1}$ " permanecem após a desidratação (Figura 2b). Já os alongamentos-OH das moléculas de água contribuem para a intensidade de absorção do par de bandas, que nesse caso específico de observação, contribuem para diferenciar espectros IV de montmorillonitas com diferentes tipos de cátions trocáveis, uma vez que a quantidade de moléculas de $\mathrm{H}_{2} \mathrm{O}$ no espaço intercamada depende dos tipos e proporções dos cátions. E apesar de as frequências absorvidas serem iguais, os padrões de absorção não são. Assim, o espectro IV-MIR "3620 e 3430 cm-1" (amostra seca, mas não desidratada) é uma impressão digital do tipo catiônico de uma montmorillonita." (Figura 2a). ${ }^{11-15,28-32}$

A banda em $3702 \mathrm{~cm}^{-1}$ é atribuída ao alongamento-OH de grupos hidroxila da superficie interior da caulinita, argilomineral presente apenas na bentonita Formosa, confirmando a análise de DRX (Figura 1). ${ }^{13}$

As intensidades de absorção das vibrações moleculares da $\mathrm{H}_{2} \mathrm{O}$ na montmorillonita são, claramente, influenciadas pelos tipos de cátions trocáveis e, consequentemente, pela quantidade de água envolvida nessa hidratação intercamada (Figura 2a). ${ }^{28} \mathrm{~A}$ valência do cátion trocável e, consequentemente, o seu tamanho ditam a quantidade de moléculas de água envolvidas nessa hidratação, o que afeta a intensidade de absorção das bandas "3620 e $3430 \mathrm{~cm}^{-1}$ ". A ordem crescente de intensidade de absorção segue um padrão característico do tipo de cátion trocável majoritário: $\mathrm{Na}^{+}<\mathrm{Mg}^{+2}<\mathrm{Ca}^{+2} .{ }^{28}$

Ao comparar as bandas "3620 e $3430 \mathrm{~cm}^{-1}$ " das quatro bentonitas brasileiras policatiônicas (Bofe, Verde, Verde escuro e Verde claro) com as bandas das três bentonitas consideradas "homocatiônicas" (Formosa, SWy-2 e SAz-1), tem-se uma forma
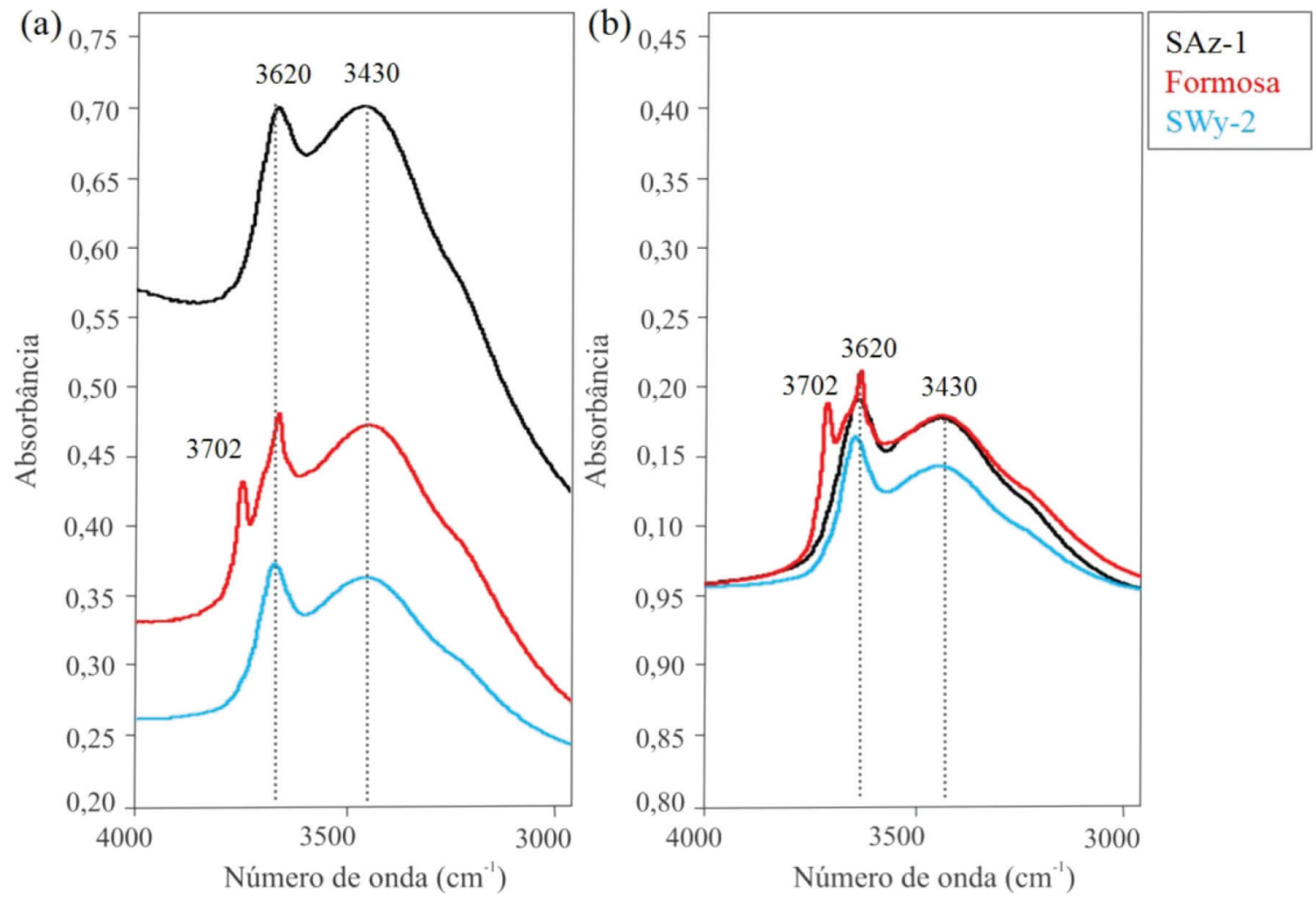

Figura 2. As duas bandas de absorção IV-MIR “3620 e $3430 \mathrm{~cm}^{-1}$ ” para as montmorillonitas SWy-2 (sódica), Formosa (magnesiana) e SAz-1 (cálcica): (a) seca a $105^{\circ} \mathrm{Ce}\left(\right.$ b) desidratada a $400{ }^{\circ} \mathrm{C}$ 
de pré-dizer semelhanças de propriedades catiônicas quanto a hidratação (Figura 3). As bentonitas Verde escuro e Verde claro apresentaram a intensidade de absorção das bandas "3620 e 3430 $\mathrm{cm}^{-1}$ " mais próxima da bentonita SAz-1, caracterizando seu caráter mais cálcico ou cálcico-magnesiano, nessa ordem. Enquanto, que a Verde se apresentou mais próxima da SWy-2, indicando seu caráter mais sódico ou sódico-magnesiano, nessa ordem. Já a bentonita Bofe se apresentou mais próxima da Formosa, indicando seu caráter mais magnesiano ou magnesiano-sódico.

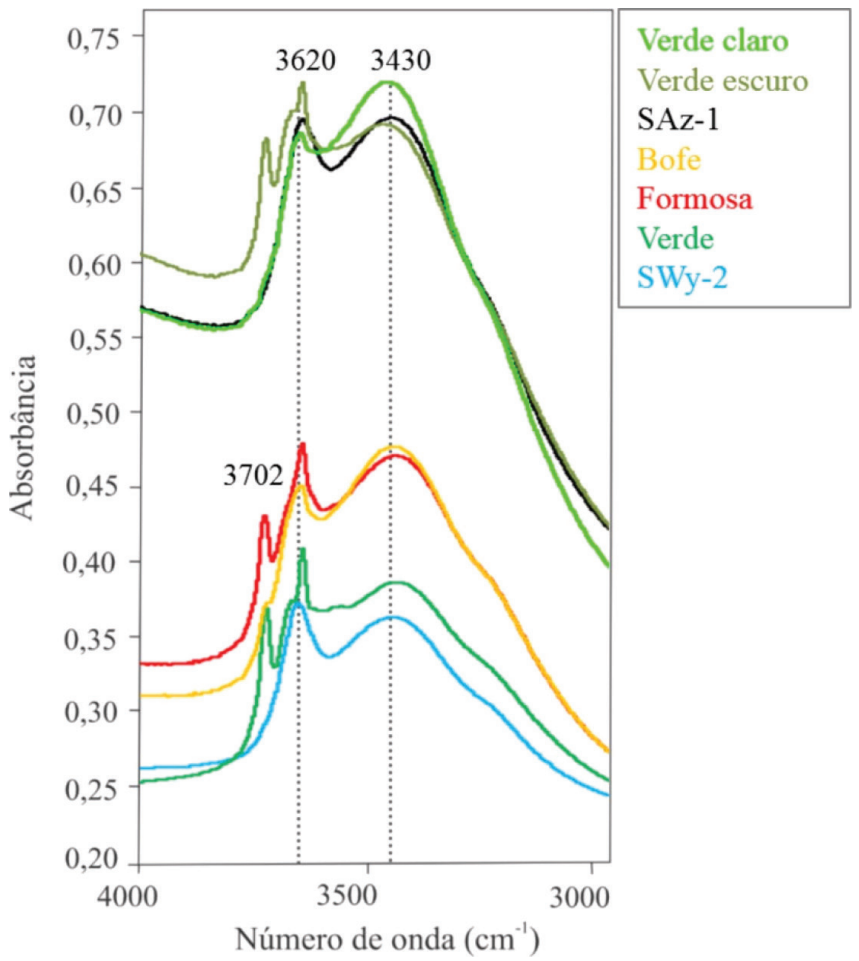

Figura 3. Comparação das bandas de absorção IV-MIR "3620 e $3430 \mathrm{~cm}^{-1}$ " das bentonitas: Formosa, SAz-1, SWy-2, Bofe, Verde, Verde escuro e Verde claro, amostras secas a $105^{\circ} \mathrm{C}$

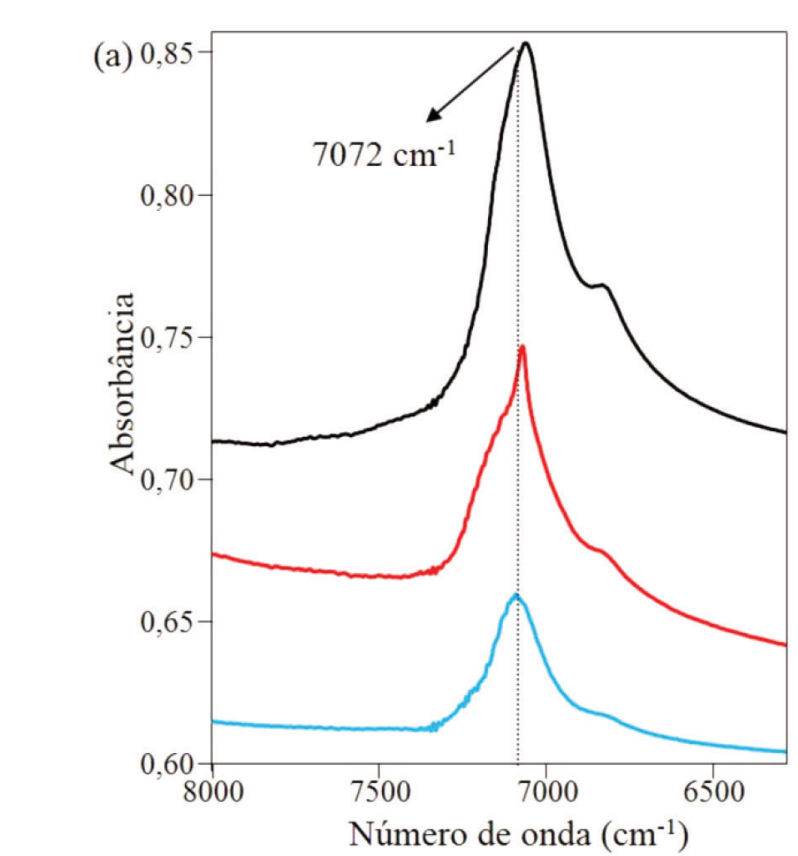

A banda de absorção IV-NIR - característica da informação "cátions trocáveis + água de hidratação" na intercamada da montmorillonita - obtida para SWy-2 (sódica), Formosa (magnesiana) e SAz-1 (cálcica) é exibida na Figura 4. A complexa banda "7072 $\mathrm{cm}^{-1}$ " é atribuída ao overtone $\left(2 \mathrm{v}_{\mathrm{OH}}\right)$ do modo de estiramento$\mathrm{OH}$ estrutural e ao overtone de $\mathrm{H}_{2} \mathrm{O}\left(2 v_{\text {água }}\right)$ ligado à superfície de oxigênios das folhas tetraédricas. $\mathrm{O}$ overtone $\left(2 \mathrm{v}_{\mathrm{OH}}\right)$ do modo de estiramento-OH estrutural, pertencente ao framework da montmorillonita anidra, é responsável pela impressão digital do argilomineral 2:1 montmorillonita, uma vez que, a banda IV-NIR "7072 $\mathrm{cm}^{-1}$ " permanece após a desidratação (Figura 4b), ${ }^{12,14,33}$ tal como as bandas IV-MIR "3620 e $3430 \mathrm{~cm}^{-1}$ ”. Já o overtone ( $\left.2 v_{\text {agua }}\right)$ contribui para a intensidade de absorção da banda (Figura 4a).

Da mesma forma que foi interpretadado para as bandas IV-MIR, a diferenciação catiônica no IV-NIR só é possível com amostras hidratadas (Figura 4a).

Ao comparar a banda " $7072 \mathrm{~cm}^{-1}$ " das quatro bentonitas brasileiras policatiônicas (Bofe, Verde, Verde escuro e Verde claro) com as bandas das três bentonitas consideradas "homocatiônicas" (Formosa, SWy-2 e SAz-1), tem-se uma forma de pré-dizer semelhanças de propriedades catiônicas quanto a hidratação (Figura 5). As bentonitas Verde escuro e Verde claro apresentaram a intensidade de absorção da banda "7072 $\mathrm{cm}^{-1}$ " mais próxima da bentonita SAz-1, caracterizando seu caráter mais cálcico ou cálcico-magnesiano, nessa ordem. Enquanto, que a Verde se apresentou mais próxima da SWy-2, indicando seu caráter mais sódico ou sódico-magnesiano, nessa ordem. Já a bentonita Bofe se apresentou mais próxima da Formosa, indicando seu caráter mais magnesiano ou magnesiano-cálcico.

\section{CONCLUSÃO}

A espectroscopia de infravermelho NIR e MIR revelou ser uma técnica eficaz na diferenciação catiônica de bentonitas por meio das bandas características "7072 cm" " e "3620 e $3430 \mathrm{~cm}^{-1}$ ", sob a condição da amostra seca-hidratada e não sob a condição anidra. É possível diferenciar os tipos cálcica, magnesiana e sódica e ainda o caráter das ditas policatiônicas, por exemplo: cálcica-magnesina, sódica-magnesiana ou cálcica-sódica-magnesiana, nessa ordem de

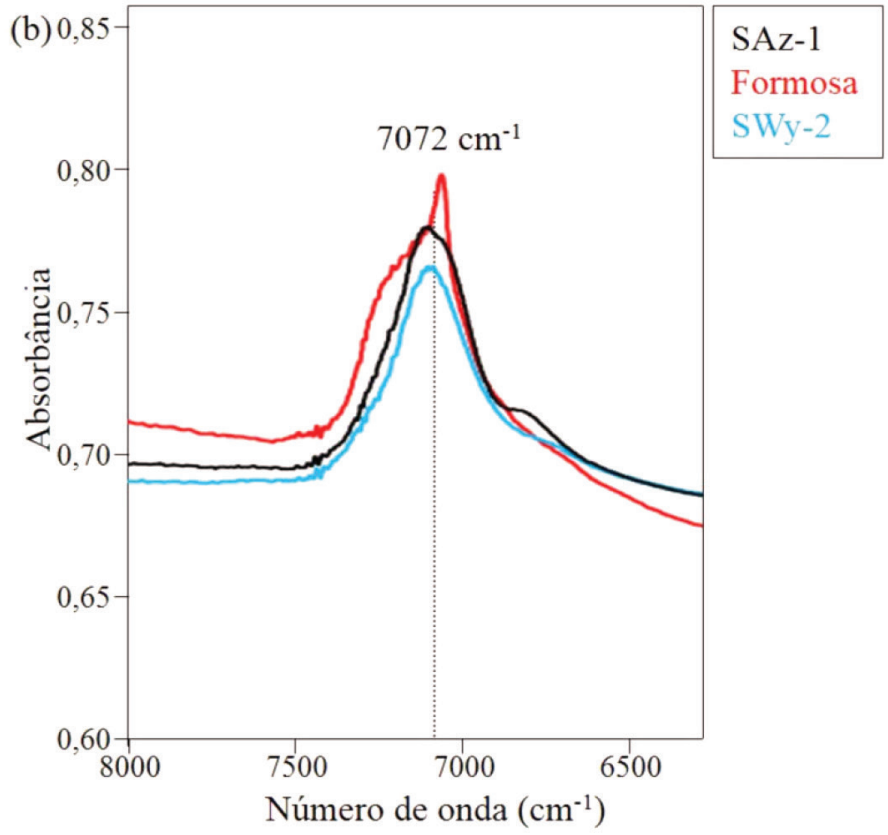

Figura 4. Banda de absorção IV-NIR “7072 $\mathrm{cm}^{-1}$ ” para as montmorillonitas SWy-2 (sódica), Formosa (magnesiana) e SAz-1 (cálcica): (a) seca a $105{ }^{\circ} \mathrm{C}$ e (b) desidratada $400{ }^{\circ} \mathrm{C}$ 


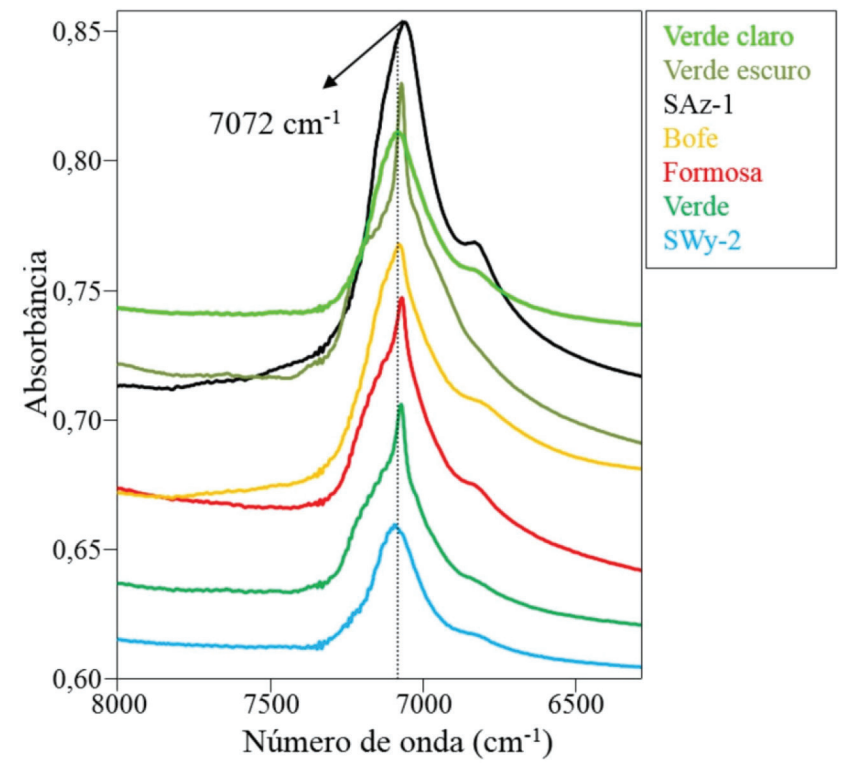

Figura 5. Comparação da banda de absorção IV-NIR "7072 $\mathrm{cm}^{-1}$ ” das bentonitas: Formosa, SAz-1, SWy-2, Bofe, Verde, Verde escuro e Verde claro, amostras secas a $105^{\circ} \mathrm{C}$

comportamento. As intensidades de absorção das vibrações-OH da água de hidratação na montmorillonita são, claramente, influenciadas pelos tipos de cátions trocáveis. A ordem crescente de intensidade de absorção segue um padrão característico do tipo de cátion trocável majoritário: $\mathrm{Na}^{+}<\mathrm{Mg}^{+2}<\mathrm{Ca}^{+2}$.

Uma das principais vantagens do uso da espectroscopia de infravermelho DRIFT-NIR é o fato de não necessitar de preparação da amostra, poupando tempo e reagentes, por isso pode ser considerada uma medida de grande contribuição científica e tecnológica, pois possibilita a diferenciação catiônica de bentonitas de uma forma prática e de baixo custo analítico.

\section{AGRADECIMENTOS}

Os autores agradecem ao Conselho Nacional de Desenvolvimento Científico e Tecnológico (CNPq) pela bolsa de mestrado da primeira autora (Processo: 130991/2018-0) e pela bolsa de produtividade em pesquisa do segundo autor (Processo:309176/2019-0); assim como, pelo apoio financeiro via Edital Universal MCTI/CNPq No 01/2016 (Processo:402427/2016-5), coordenado pelo segundo autor, e $\mathrm{N}^{\circ}$ 01/2018 (Processo: 429756/2018-6), coordenado pelo terceiro autor.

\section{REFERÊNCIAS}

1. Murray, H. H.; Applied Clay Mineralogy: Developments in Clay Science, $1^{\text {st }}$ ed., Elsevier, 2006.

2. Tournassat, C.; Bizi, M.; Braibant, G.; Crouzet, C.; J Colloid Interf Sci 2011, 364, 443.

3. Choo, K. Y; Bai, K.; Appl. Clay Sci. 2016, 126, 153.
4. Chen, Q.; Zhu, R.; Ma, L.; Zhou, Q.; Zhu, J.; He, H.; Appl. Clay Sci. 2017, 135, 129.

5. ABIFA; Bentonita para Fundição - Especificação, São Paulo, 1991. (CEMP E-04. ABIFA)

6. Santos, P. S.; Ciência e tecnologia de argilas, $2^{\mathrm{a}}$ ed., Vol. 1, Edgar Blücher, 1992.

7. Eisenhour, D. D.; Brown, R. K.; Elements 2009, 5, 83.

8. DNPM; Sumário Mineral, Brasília, 2016.

9. Lebedenko, F; Plée, D.; Appl. Clay Sci. 1988, 3, 1.

10. Karagüzel, C.; Çetinel, T.; Boylu, F.; Çinku, K.; Çelik, M.S.; Applied Clay Science. 2010, 48, 398.

11. Bishop, J. L.; Pieters, C. M.; Edwards, J. O.; Clays and clay minerals 1994, 42,702

12. Madejová, J.; Bujdák, J.; Petit, S.; Komadel, P.; Clay Minerals 2000, 35, 753.

13. Madejová, J.; Komadel, P.; Clay and Clay Minerals 2001, 49, 410.

14. Gates, W.P.; Petit, S.; Madejová, J. Infrared and Raman Spectroscopies of Clay Minerals, Developments in Clay Science, 2017, vol. 8, p. 200.

15. Pavia, D.L.; Lampman, G.M.; Kriz, G.S.; Vyvyan, J.R. Introdução à Espectroscopia, Tradução da $4^{\mathrm{a}}$ ed. norte americana: Introduction to Spectroscopy, Cengage Learning, 2009.

16. Amorim, L. V.; Gomes, C. M.; Lira, H. L.; França, K. B.; Ferreira, H. C.; Materials Research 2004, 7, 583.

17. Moraes, D. S.; Angélica, R. S.; Costa, C. E. F.; Rocha Filho, G. N.; Zamian, J. R.; Applied Clay Science 2010, 48, 475.

18. Silva, R. A. M.; Paz, S. P. A.; Angélica, R. S.; Resumos da XV International Clay Confere, Rio de Janeiro, Brasil, 2013.

19. Paz, S. P. A.; Angélica, R. S.; Neves, R. F.; Neumann, R.; Costa, G. M.; Cerâmica 2011, 57, 444.

20. Paz, S. P. A.; Angélica, R. S.; Neves, R. F. Clays and Clay Minerals 2012, 60, 265.

21. EMBRAPA; Manual de métodos de análises químicas para avaliação da fertilidade do solo, Documento nº 3, Rio de Janeiro, 1998.

22. Bergaya, F.; Lagaly, G. Handbook of Clay Science: Developments in Clay Science. vol. 1, 1st edition, Elsevier, Amsterdam, 2006.

23. Moore, D.M.; Reynolds, R.C.; X-Ray Diffraction and the Identification and Analysis of Clay Minerals. Oxford University Press, 1989.

24. Grim, R. E.; Clay Mineralogy. McGraw-Hill Book Co. Inc., New York, 1968.

25. Yildiz, A.; Kuscu, M.; Clay Minerals 2007, 42, 399.

26. Aguiar, M. R. M. P.; Novaes, A. C.; Guarino, A. W. S.; Quim. Nova 2002, 25, 1145.

27. Stoch, L.; Sei. Géol. Mém. 1990, 89, 111.

28. Xu, W.; Johnston, C. T.; Parker, P.; Agnew, S. F.; Clays and Clay Minerals 2000, 48, 120.

29. Zviagina, B. B.; McCarty, D. K.; Środon, J.; Drits, V. A.; Clays and Clay Minerals 2004, 52, 399

30. Madejová, J.; Vibrational Spectroscopyn 2003, 31, 1.

31. Russell, J. D.; Farmer, V. C.; Clay Min. Bull. 1964, 5, 443.

32. Farmer, V. C.; The layered silicates. In: Farmer, V. C. (Eds.), The Infrared Spectra of Minerals. The Mineralogical Society Monograph 4, London, 1974.

33. Bizovská, V.; Pálková, H.; Madejová, J. Clays and Clay Minerals 2016, 64,571 . 